\title{
Papers
}

\section{Health effects of housing improvement: systematic review of intervention studies}

\author{
Hilary Thomson, Mark Petticrew, David Morrison
}

\begin{abstract}
Objective To review the evidence on the effects of interventions to improve housing on health. Design Systematic review of experimental and non-experimental housing intervention studies that measured quantitative health outcomes.

Data sources Studies dating from 1887, in any language or format, identified from clinical, social science, and grey literature databases, personal collections, expert consultation, and reference lists. Main outcome measures Socioeconomic change and health, illness, and social measures.

Results 18 completed primary intervention studies were identified. 11 studies were prospective, of which six had control groups. Three of the seven retrospective studies used a control group. The interventions included rehousing, refurbishment, and energy efficiency measures. Many studies showed health gains after the intervention, but the small study populations and lack of controlling for confounders limit the generalisability of these findings.

Conclusions The lack of evidence linking housing and health may be attributable to pragmatic difficulties with housing studies as well as the political climate in the United Kingdom. A holistic approach is needed that recognises the multifactorial and complex nature of poor housing and deprivation. Large scale studies that investigate the wider social context of housing interventions are required.
\end{abstract}

\section{Introduction}

Poor housing has been used both as an indicator of poverty and as a target for interventions to improve public health and reduce inequalities in health. ${ }^{1}$ Although housing still has a prime place on the health inequalities agenda, it also has wider importance because small health effects can have a large impact at the population level.

Policy makers are also increasingly interested in measuring the health effects of social interventions (such as social housing) and in gathering evidence to shape policy. ${ }^{23}$ Much of the research investigating the links between housing and health has been cross sectional, and these studies have shown strong independent associations between housing conditions and health. However, results of studies in small areas are difficult to generalise to other contexts. Observational studies have also shown strong independent associations between poor housing and poor health, but their results remain open to debate and interpretation. ${ }^{4}$

Experimental studies of the health impacts of housing would provide stronger evidence. The randomised controlled trial has been regarded as the gold standard experimental model to show the effects of interventions in medicine. Such trials, however, are less common in housing research, where there is less of a history of experimentation. ${ }^{5}$ We carried out a systematic review of intervention studies of the health effects of housing improvement.

\section{Methods}

Search strategy

We searched the following databases: ASSIA (Applied Social Science Index and Abstracts, 1987-2000), CAB Health (1973-2000), DHSS-DATA (1983-2000), Embase (1974-2000), HealthSTAR (1975-2000), Medline (19662000), PAIS (Public Affairs Information Service, 1976-2000), PsycINFO (1887-2000), SIGLE (System for Information on Grey Literature in Europe, 1980-2000), Social SciSearch (1972-2000), Sociological Abstracts (1963-2000), Social Science Citation Index (1981-2000), Urbadisc, Cochrane Controlled Trials Database 2000 Issue 2, IBSS (International Bibliography of the Social Sciences), SPECTR (Social, Psychological, Educational, and Criminological Controlled Trials Register, searched December 2000), and the world wide web. Full details of the search strategy are available from the authors.

We hand searched the bibliographies of all reports, papers, and text books that we reviewed. We also requested information on unpublished and ongoing studies from subscribers to the Housing Studies Association newsletter and email list and the Health Action Zone discussion group. HT contacted health authority housing departments, academic departments in the United Kingdom, local authorities, and housing associations. We also asked delegates at an international housing conference for details of suitable studies, either completed or ongoing.

\section{Selection}

We sought primary studies in any language that used experimental or quasi-experimental approaches to examine the effects of housing improvements. These included randomised controlled trials and observational studies that used prospective or retrospective

\section{Medical Research Council Social and Public Health Sciences Unit, Glasgow G12 8RZ \\ Hilary Thomson higher scientific officer Mark Petticrew associate director David Morrison specialist registrar in public health medicine \\ Correspondence to: H Thomson hilary@msoc.mrc. gla.ac.uk}

BMJ 2001;323:187-90

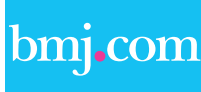

Tables giving full details of the included and ongoing studies are available on the BMJ's website 
Criteria for assessing strength of evidence (adapted from NHS Centre for Reviews and Dissemination method) ${ }^{6}$

Level A: prospective study, follow up rate $>\mathbf{8 0} \%$ and for $\geqslant 6$ months

Randomised controlled trial, or controlled study with comparable control group

Objective assessment of health outcome(s)

Level B: prospective study with control group

Limited control of confounding

Appropriate assessment of health outcomes

Level C: prospective and retrospective studies that did not adjust for confounding factors

Studies with biased assessment of health outcomes

measures of health. Our outcome measures were based on a social model of health and included socioeconomic changes and illness based outcomes. Housing interventions were defined as rehousing, and all physical changes to housing were defined as infrastructure-for example installation of heating, insulation, double glazing, and general refurbishment.

We excluded cross sectional studies that did not investigate the effects of housing improvement before and after the intervention. We did not include interventions to improve the indoor environment through furniture or indoor equipment (such as vacuuming, mattresses, and air purifiers) unless the evaluation measured changes in residents' health and the measures were part of a package of interventions that included improvements to the house itself. Environmental studies of the adverse effects of lead, urea formaldehyde foam, poor air quality, allergens, or radon were not included. At least two reviewers independently screened all abstracts identified by the searches.

\section{Assessment of validity assessment and data abstraction}

Three reviewers critically appraised the included studies according to the criteria (box). Studies graded as C were not considered in the final assessment of the evidence. When reviewers' conclusions differed, the study was reviewed jointly by three reviewers. Data were abstracted by one reviewer (HT) and checked by a second reviewer (MP). When data on the group of interest were not given in the publication, we calculated them if possible-for example, new $\mathrm{P}$ values were calculated using the relevant sample sizes.

\section{Results}

We identified 18 completed intervention studies (see $B M J$ 's website for details), ${ }^{7-29}$ the earliest dating from $1936 .{ }^{15}$ Six studies were identified from electronic databases (figure). Three studies examined the health impacts of rehousing based on medical need, ${ }^{7-10} 11$ examined the health effects of rehousing or refurbishment and renovation, ${ }^{11-23}$ and four assessed energy efficiency measures. ${ }^{24-29}$ Seven studies assessed housing improvement in the context of area or community regeneration. ${ }^{11} 12$ 15-17 19-21

Eleven studies were prospective, of which six used control groups. ${ }^{7811-152627}$ Three of the seven retrospective studies used a control group. ${ }^{20} 212829$
We also identified 14 ongoing housing intervention studies based in the United Kingdom (see BMJ's website for details). These are investigating similar interventions to the completed studies. Seven of these ongoing studies are prospective and controlled; one is using a randomised stepped wedge design. ${ }^{30}$

\section{Medical priority rehousing}

All three studies of rehousing on the basis of medical need found improvements in self reported physical and mental health. However, the only prospective study was small, ${ }^{78}$ and no study controlled for the effects of possible confounding variables. One study examined the effects on use of health services and found no clear pattern. ${ }^{9}$

\section{Rehousing, refurbishment and relocation or} community regeneration

Two prospective controlled studies reported beneficial effects of rehousing or refurbishment on health outcomes, including improvements in mental health. ${ }^{11-14}$ Only one study had controlled for confounding. This study showed an initial increase in illness episodes in the intervention group at 9 months. At 18 months, however, the intervention group showed a larger reduction in illness episodes compared with the control group, although the absolute difference was small (29 episodes/1000 people) and the rate of follow up was not stated. ${ }^{11}{ }^{12}$ The other prospective controlled study reported improvements in mental and physical health, but the study was small and the comparability of the control group is unclear. ${ }^{13}{ }^{14}$

\section{Energy efficiency measures}

Although the four studies that we identified all found that energy efficiency measures improve respiratory and other symptoms, only one study adjusted for potential confounding variables. ${ }^{27}$ High rates of attrition in this and most other studies limit the generalisability of these findings.

\section{Use of health services and social effects}

Some studies assessed the effects of improving housing on use of health services; decreased visits to the general practitioner, reduced likelihood of inpatient and outpatient use of health services, and reduced prescribing of hypnotic and respiratory drugs were reported. None of the evidence for these effects came from methodologically robust prospective controlled studies.

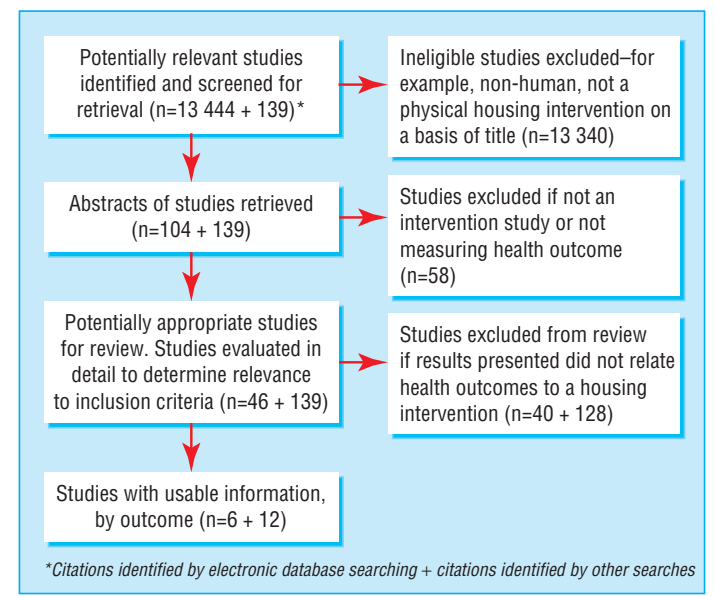

Trial flow 
Broader social impacts of housing improvement were reported in some studies, including improvements in social outcomes, such as perceptions of safety and social and community participation..$^{1617}{ }^{19} 23$ One small study reported a small increase in social support after the intervention. ${ }^{19}$ Two studies that examined the effects of housing improvement in the context of area regeneration, reported that residents' concerns about local crime were reduced..$^{17}{ }^{23}$ Another small study reported that fewer days were lost from school because of asthma after heating improvements. ${ }^{25}$

\section{Discussion}

We found few studies examining the effects of housing improvements on health, and the quality of the studies identified was generally poor. Improvements have been reported in overall self reported physical and mental health, as well as reductions in symptoms and use of health services. There is also some evidence of improvements in broad indicators of social inclusion such as neighbourliness and fear of crime. However, because of the methodological limitations of the studies, it is impossible to specify the nature and size of health gain that may result from a specific housing improvement. In particular, there are few large prospective controlled studies, and many studies are now quite old.

The effect of publication bias on our study also needs considering. Given the small positive effect sizes and small sample sizes, any summary of the published studies may overestimate the effects of housing improvements. In addition, the fact that we identified only six out of the 18 included studies using electronic databases suggests that systematic reviews of nonclinical interventions need to develop specially tailored search strategies.

\section{Difficulties in studying housing and health}

Reasons for the lack of studies into the effects of housing on health may include methodological difficulties and political obstacles. There are many methodological difficulties inherent in assessing the health effects of housing interventions. Poor housing conditions often exist alongside other forms of deprivation, and housing interventions rarely occur in isolation. This may affect the sociodemographics of an area and make before and after comparisons problematic. ${ }^{20}$ Moreover, response and follow up rates in studies of deprived areas are often low.

More generally, the experimental approach to housing research has been criticised for being reductionist and ignoring the multifactorial nature of causality in housing, deprivation, and health. ${ }^{31}$ Nevertheless, broad generalisations about the link between deprivation and ill health can have only a limited role in informing specific policy decisions. ${ }^{32}$ Evidence of the effectiveness and cost effectiveness of specific interventions is therefore particularly important. Assembling such evidence requires a holistic approach, combining quantitative and qualitative methods and taking into account a range of possible influences and mechanisms. ${ }^{33}$ Although there is a long tradition of this type of evaluation in the United States, it has rarely been attempted in the United Kingdom. ${ }^{34}$ In 1989, Smith recommended that housing research should embrace a public health approach and include more multidisciplinary studies. ${ }^{35}$ This is now starting to happen. Of the ongoing studies we identified, eight are collaborations between housing and health agencies and academics.

Political obstacles to conducting housing research may also exist. Traditionally, policy makers in the United Kingdom have not had access to much evidence on the health effects of social interventions. This lack of evidence and the methodological limitations of existing studies may be used by governments to absolve themselves of responsibility for improving housing. However, the current Labour government's interest in identifying "what works," and its emphasis on joined up decision making, may facilitate a less fragmented approach to tackling deprivation. The number of current collaborative housing studies suggests a greater willingness to use such joined up approaches. What is also needed is robust evidence of their effects.

\section{Other evidence}

Sources of evidence other than experimental studies are also important. Longitudinal studies have been recommended as a useful, if expensive, study design in evaluating complex interventions such as housing. ${ }^{35}$ For example, recent results from the 33 year follow up from the longitudinal national childhood developmental study show that poor housing adversely affects health in later life. The study found a dose-response relation, with multiple housing deprivation leading to greater risk of disability or severe ill health in later life. ${ }^{36}$ Data from the Boyd-Orr cohort also show that childhood housing conditions have an effect on adult health independent of the effects of socioeconomic deprivation. ${ }^{37}$

Further research is also needed into the direction of the relation between health and housing. Previous work has suggested that poor health can negatively affect housing opportunities. ${ }^{38}$

Although our review focused on major housing improvements, good evidence exists from systematic reviews that other interventions to improve health inside the home may be effective. Among these are interventions to reduce house dust mites and to reduce accidents among children and elderly people. ${ }^{39-41}$

\section{Conclusion}

The basic human need for shelter makes the relation between poor housing and poor health seem self evident. ${ }^{42}$ Despite, or perhaps because of, this intuitive relation, good research evidence is lacking on the health gains that result from investment in housing. We know little about the mechanisms of interaction of social factors and the effects of poor housing over the lifecourse. There is also a lack of comparative information on the costs and effects of specific housing improvements, such as central heating or major refurbishment. It is this type of evidence that is likely to be most valuable to policy makers and housing providers. Large scale studies that investigate the wider social context of housing improvements and their comparative effectiveness and cost effectiveness are now required.

We thank Professor Sally Macintyre for helpful comments on the manuscript, Julie Glanville and Su Golder for help with the searches, and Mary Robins for librarian support.

Contributors: HT contributed to the search strategy of the review, collection, and analysis of the data, and writing the paper 


\section{What is already known on this topic}

Many epidemiological studies have described associations between poor housing and health

\section{What this study adds}

18 studies were reviewed that studied the health effects of housing improvements

Most studies found some health gains

Small populations and lack of control for confounders limits the generalisability of the findings

More large scale, controlled studies of housing interventions are needed to give qualitative and quantitative data

and is the guarantor. MP contributed to the collection and analysis of the data and writing the paper. DM contributed to reviewing the studies and writing the paper.

Funding: The authors are funded by the Chief Scientist Office of the Scottish Executive Department of Health.

Competing interests: None declared.

1 Gauldie E. Cruel habitations: a history of working class housing, 1780-1918. London: Allen and Unwin, 1974

2 Acheson D. Independent inquiry into inequalities in health report. London: HMSO, 1998

3 Secretary of State for Health. Saving lives: our healthier nation. London: HMSO, 1999.

4 Wilkinson D. Poor housing and ill health: a summary of the research evidence. Edinburgh: Scottish Office Central Research Unit, 1999.

5 Mant D. Understanding the problems of health and housing research. In: Burridge R, Ormandy D, eds. Unhealthy housing; research, remedies and reform. London: $\mathrm{E}$ and $\mathrm{F} \mathrm{N}$ Spon, 1993:3-21.

6 NHS Centre for Reviews and Dissemination. A systematic review of public water fluoridation. York: NHSCRD, University of York, 2000.

7 Elton P, Packer J. Neurotic illness as grounds for medical priority for rehousing. Public Health 1987;101:233-42.

8 Elton P, Packer J. A prospective randomised trial of the value of rehousing on the grounds of mental ill-health. J Chron Dis 1986;39:221-7.

9 Smith SJ, Alexander A, Easterlow D. Rehousing as a health intervention: miracle or mirage? Health and Place 1997;3:203-16.

10 Cole O, Farries JS. Rehousing on medical grounds: assessment of its effectiveness. Public Health 1986;100:229-35.

11 Wilner DM, Price-Walkley R, Glasser MN, Tayback M. The effects of housing quality on morbidity: preliminary findings of the Johns Hopkins longitudinal study. Am J Public Health 1958;48:1607-15.

12 Wilner DM, Price-Walkley R, Schram JM, Pinkerton TC, Tayback M. Housing as an environmental factor in mental health: the Johns Hopkins longitudinal study. Am J Public Health 1960;50:55-63.

13 Carp FM. Impact of improved housing on morale and life satisfaction. Gerontologist 1975;15:511-5.

14 Carp FM. Impact of improved living environment on health and life expectancy. Gerontologist 1977;17:242-9.

15 McGonigle G, Kirby J. Poverty, nutrition and the public health. In: Poverty and public health. London: Gillencz, 1936:108-29.

16 Blackman T, Harvey J, Lawrence M, Simon, A. Neighbourhood renewal and health: evidence from a local case study. Health and Place 2001 (in press).
17 Ambrose P. A drop in the ocean; the health gain from the Central Stepney SRB in the context of national health inequalities. London: Health and Social Policy Research Centre, University of Brighton, 2000.

18 Wells N. Housing quality and women's mental health: a 3 wave longitudinal study. In: Housing in the 21st century. Gavle, Sweden: European Network for Housing Research, 2000.

19 Halpern D. Improving mental health through the environment: a case study. In: Mental health and the built environment: more than bricks and mortar? London: Taylor and Francis, 1995:173-233.

20 Walker R, Bradshaw N. The Oakdale renewal scheme: use of prescribing data to assess the impact on the health of residents. Cardiff: Gwent Health Authority and Welsh School of Pharmacy, 1999.

21 Wambem DB, Piland NF. Effects of improved housing on health in South Dos Palos, California. Health Services Report 1973;88:47-58.

22 Baba K, Baba M, Mizuno H, Tsumura C. Research into the achievemen and impact of "assistance programme for healthy housing" of Edogawa ward. Ann Jap Public Health 1994;41:404-13.

23 Woodin S, Delves C, Wadhams C. Just what the doctor ordered: a study of housing, health and community safety in Holly Street, Hackney. London: Comprehensive Estates Initiative, Hackney Housing Department, 1996.

24 Somerville M, Mackenzie I, Owen P, Miles D. Housing and health: the Cornwall intervention study. St Austell: Cornwall and Isles of Scilly Health Authority, Energy Action Grants Agency Charitable Trust, 1999.

25 Somerville M, Mackenzie I, Owen P, Miles D. Housing and health: does installing heating in their home improve the health of children with asthma? Public Health 2000;114:434-40.

26 Hopton J, Hunt S. The health-effects of improvements to housing-a longitudinal-study. Housing Studies 1996;11:271-86.

27 Iversen M, Bach E, Lundqvist GR. Health and comfort changes among tenants after retrofitting of their housing. Environment International $1986 ; 12: 161-6$.

28 Green GJG. Housing, poverty and health: the impact of housing investment on the health and quality of life of low income residents. Open House International 1999:24:41-53.

29 Green G, Ormandy D, Brazier J, Gilbertson J. Tolerant building: the impact of energy efficiency measures on living conditions and health status. In: Nicol F, Rudge J, eds. Cutting the cost of cold. London: E and F N Spon, 2000.

30 Somerville M. The Torbay housing project. National Research Register. www.update-software.com/nrr/CLIBINET.EXE? $\mathrm{A}=1 \& \mathrm{U}=1001 \& \mathrm{P}=$ 10001 (accessed 9 May 2001)

31 Hunt S. Damp and mouldy housing: a holistic approach. In: Burridge R, Ormandy D, eds. Unhealthy housing: research, remedies and reform. London: E and F N Spon, 1993:67-89.

32 Thunhurst C. Using published data to assess health risks. In: Burridge R, Ormandy D, eds. Unhealthy housing: research, remedies and reform. London: E and F N Spon, 1993:23-38

33 Baum F. Research public health: behind the qualitative-quantitative methodological debate. Soc Sci Med 1995;40:459-68.

34 Oakley A. Experimentation and social interventions: a forgotten but important history. BMJ 1998;317:1239-42.

35 Smith SJ. Housing and health: a review and research agenda. Glasgow: Centre for Housing Research, University of Glasgow, Economic Social Research Council, 1989

36 Marsh A, Gordon D, Pantazis C, Heslop P. Home sweet home? The impact of poor housing on health. Bristol: Policy Press, 1999.

37 Dedman D, Gunnell D, Davey-Smith G, Frankel S. Childhood housing conditions and later mortality in the Boyd Orr cohort. $J$ Epidemiol Community Health 2001;55:10-5.

38 Smith SJ. Health status and the housing system. Soc Sci Med 1990;31:75362.

39 NHS Centre for Reviews and Dissemination. Preventing falls and subsequent injury in older people. Effective Health Care 1996;2(6).

40 NHS Centre for Reviews and Dissemination. Preventing unintentiona injuries in children and young adolescents. Effective Health Care 1996;2(5)

41 Hammarquist C, Burr ML, Gotzsche PC. House dust mite control measures for asthma. Cochrane Database Syst Rev 2000;(2):CD001187.

42 Burridge R, Ormandy D, eds. Unhealthy housing: research, remedies and reform. London: $\mathrm{E}$ and $\mathrm{F} \mathrm{N}$ Spon, 1993.

(Accepted 25 April 2001)

\section{Email submissions from outside the United Kingdom}

We offer an email submission service for authors from outside the UK. The address is papers@bmj.com

Ideally our email server would link seamlessly with our manuscript tracking system, but for now it does not, which is why we are offering the service only to authors outside the UK. Most post in the UK arrives the next day, so UK authors have the least to gain in speed of delivery from email delivery. As soon as our systems improve we will invite email submissions from everyone.

If you choose to send your submission by email please would you send the text and any tables and figures as attached files, together with a covering letter giving all your contact details (postal address, phone, fax, and email address). We can read files created with most word processing, graphics, and spreadsheet programs.

When your submission is received in our email box you will receive an automatic acknowledgment to show that it has arrived. If the submission is incomplete we will contact you and ask you to resend the missing information.

Once the submission is complete we will register it on our manuscript tracking system and you will receive a standard acknowledgment in the post.

Letters to the editor should continue to be sent direct to bmj.com as rapid responses or toletters@bmj.com 